Association for Information Systems

AIS Electronic Library (AISeL)

Wirtschaftsinformatik 2021 Proceedings

Track 3: Student Track

\title{
Leave No One Behind: Design Principles for Public Warning Systems in Federalism
}

\author{
Anna Katharina Frische \\ Westfälische Wilhelms-Universität Münster \\ Julia Felicitas Kirchner \\ Westfälische Wilhelms-Universität Münster \\ Caroline Pawlowski \\ Westfälische Wilhelms-Universität Münster \\ Sebastian Halsbenning \\ Westfälische Wilhelms-Universität Münster \\ Jörg Becker \\ Westfälische Wilhelms-Universität Münster
}

Follow this and additional works at: https://aisel.aisnet.org/wi2021

Frische, Anna Katharina; Kirchner, Julia Felicitas; Pawlowski, Caroline; Halsbenning, Sebastian; and Becker, Jörg, "Leave No One Behind: Design Principles for Public Warning Systems in Federalism" (2021). Wirtschaftsinformatik 2021 Proceedings. 4.

https://aisel.aisnet.org/wi2021/XStudent/Track03/4

This material is brought to you by the Wirtschaftsinformatik at AIS Electronic Library (AISeL). It has been accepted for inclusion in Wirtschaftsinformatik 2021 Proceedings by an authorized administrator of AIS Electronic Library (AISeL). For more information, please contact elibrary@aisnet.org. 


\title{
Leave No One Behind: Design Principles for Public Warning Systems in Federalism
}

\author{
Anna Katharina Frische ${ }^{1}$, Julia Felicitas Kirchner ${ }^{1}$, Caroline Pawlowski ${ }^{1}$, \\ Sebastian Halsbenning ${ }^{1}$, and Jörg Becker ${ }^{1}$ \\ ${ }^{1}$ University of Münster, ERCIS, Münster, Germany \\ \{anna.frische, julia.kirchner, caroline.pawlowski\}@uni-muenster.de \\ \{halsbenning, becker\}@ercis.de
}

\begin{abstract}
The effectiveness of public warning systems (PWS) can be challenged by federal structures as the failure of the first nationwide German "Warntag" (Warning Day) showed. By designing PWS to address specific challenges of federal systems, the effectiveness of public warning might be improved. In this paper, we derive design principles for PWS which aim to address these specific challenges. Based on a thorough literature review, challenges regarding responsibility, coordination, and interoperability, as well as functional and technical requirements for PWS in federal systems were identified. By applying a design-oriented research approach, 16 design principles in the categories strategy and governance, standards and templates, and technology are articulated. The research provides guidance for responsible authorities in federal systems for the implementation or evaluation of public warning systems.
\end{abstract}

Keywords: public warning system, public warning, federalism, design principles, design science

\section{Introduction}

In 2020, public warning received public attention in Germany when the first nationwide "Warntag" (Warning Day) was declared a failure by the Ministry of Interior [1]. One of the reasons was that the warning apps NINA and KATWARN pushed warning messages delayed or not at all, as warning messages were accidentally triggered simultaneously on the federal, state, and local level [2]. As public warning systems (PWS) and administrative and governance structures are directly linked to each other, state structures can challenge the effectiveness of PWS [3]. For example, the German PWS is regarded as highly influenced by the federal character of the civil protection responsibility [3, 4]. Every citizen must be entitled to receive a warning of equal quality if they are potentially affected by an emergency. From a federal perspective, this means an increased need for guidelines to ensure that the same quality of warning is delivered throughout the federal system [5].

This paper addresses these challenges of public warning in a federal administrative system by the development of design principles for public warning systems in federal administrative systems. The design principles serve the purpose of guiding through the 
implementation of a new PWS. To meet the research goal appropriately, this paper follows a design-oriented research approach proposed by Österle et al. [6].

The following section of this paper introduces the research background and relevant concepts regarding public warning, including the means of public warning, challenges for public warning in a federal system, and the requirements for public warning. In the next section, the paper's overall research design to achieve the research goal is explained. Afterward, design principles derived from prioritized requirements are presented as the results of the research and applied to the German case. Finally, the results are discussed, including the study's limitations and implications for research and practice.

\section{Research Background}

\subsection{Public Warning}

Public warning is "the provision of timely and effective information, through identified institutions, that allows individuals exposed to a hazard to take action to avoid or reduce their risk and prepare for effective response" [7]. To obtain relevant information in risk situations, four types of communication can be classified [8]: (1) from citizen to authorities, (2) among authorities, (3) from authorities to citizens, and (4) among citizens. This paper focuses on the third type of communication, which is achieved by PWS [8], through which authorities provide the citizens with relevant emergencyrelated information as well as suggested actions to be protected in risk situations [8].

Means of informing, alerting, and warning the population have changed over the years. However, the traditional warning system sirens are still in use since they are recognized as a "universal language" for an emergency and therefore make people aware of an occurring emergency $[9,10]$. However, sirens have limited capabilities to provide the population with more information about the emergency and could fail to operate due to their outside outdoor location [9]. Through the information era, people impose high demands in the information flow about events before acting, as they are used to being consistently provided with sufficient information [3]. Established and new media, like radios, warning-apps, or TV broadcasts, can warn the population and simultaneously advise the necessary action in time [10].

Means of informing, alerting, and warning the population have changed over the last couple of years. The traditional warning system, a siren is still in usage, since it is recognized as a "universal language" for an emergency and therefore makes people aware of an occurring emergency [9, 19]. However, the siren is limited in its capabilities, as it is not capable of notifying the population with more information about the emergency and due to its outside location, could fail to operate [9]. Additionally, through the information era, people impose high demands in the information flow about events before acting, as they are used to constantly being provided with sufficient information [3]. New media, like radios, warning-apps, or TV broadcast can warn the population and simultaneously advice the required action in time [10]. 


\subsection{Public Warning and Federalism}

The nature of a public warning system is closely related to the administration and governance structures of the country in which it is applied [3]. A state's complex and often contradictory social and administrative relationships shape and influence its actions and responses to disasters [11]. Therefore, managing risk in multilevel systems is strongly influenced by policy decisions and institutions on multiple administrative levels.

As they differ in administrative and governance structures, each federal administrative system faces its own administrative and governance challenges, influencing the adopted solutions for public warning significantly [3]. In the case of multilevel systems, complexity increases, and challenges regarding responsibility [12, $13]$, coordination $[12,14,15]$ and interoperability $[3,15,16]$ occur. In the case of multilevel systems, complexity increases. The literature review revealed responsibility $[12,13]$, coordination $[12,14,15]$, and interoperability $[3,15,16]$ as the main challenges of public warning in federal systems.

Responsibility. In a multilevel system, responsibilities are usually delegated among different federal and state departments, and critical conflicts and gaps can occur within these relationships [15]. In multilevel systems, clear responsibilities, especially for warning system implementation, need to be defined [13].

Coordination. In a multilevel system, coordination ensures that all levels of the system work together in a synchronized manner. This is one of the most prevailed challenges of public warning in multilevel systems and inadequate coordination between different levels is a significant barrier for the functioning of warning systems [13].

Interoperability. Another challenge related to public warning in a federal system is interoperability. Barriers to the interoperability of public warning systems are higher when civil protection is decentralized [3]. The literature describes different perspectives and levels of interoperability. In contrast, some authors address interoperability in regards to the need for interoperable communication systems [15], and others stress the importance of interoperability of neighboring countries [9] and Europe-wide interoperability of public warning and alert systems [17].

There are also distinct advantages concerning public warning in federal systems. Federal structures and the resulting necessity to involve multiple actors in public warning processes can lead to a constructive competition of ideas, and productive knowledge exchange among institutions [14]. A positive outcome of complex governance networks is that actors from multiple levels are urged to jointly reach decisions on parallel activities or coordinative measures, which might facilitate common standards in civil protection [14].

\section{$3 \quad$ Research Design}

To meet our research goal, we follow the design-oriented research approach by Österle et al. [6]. Design-oriented research explicitly focuses on solving problems by 
developing IT artifacts in four phases. In the first phase, Analysis, the research problem is identified, and the methods to be applied for solving the problem are planned. In the following phase, Design, the actual development of the artifact is conducted, which is critically tested in the third phase-the Evaluation. Lastly, the results of the research are disseminated during the fourth phase, Diffusion.

For the Analysis, we made practical and scientific considerations and further investigated the areas of public warning and federalism. As a result of this, we uncovered several competing characteristics of warning systems and federal structures underlining the relevance of our investigations, which finally led to the formulation of our research goal. To address this goal, we firstly derived requirements for public warning systems in federal systems by conducting a literature review and an expert interview.

The literature review was conducted according to Webster and Watson [18]. The literature consisted of relevant articles from the databases Web of Science and Scopus between 2010 to 2020. A total number of 21 academic sources were considered relevant to the previously introduced problem. Additionally, a manual search of the titles in all volumes and issues between 2010 and 2020 of the Journal of Contingencies and Crisis Management and the Journal of Emergency Management and Homeland Security was conducted, which resulted in two additional relevant academic sources. Finally, the sources identified in the first two steps were used for backward and forward research, which added another five sources to the literature review.

The literature review resulted in a set of relevant academic sources that covered functional as well as technical requirements for PWS in general [18], as well as specific requirements that address the previously identified challenges of responsibility, coordination, and interoperability of public warning for federal administrative systems. Requirements from all sources were synthesized and evaluated regarding their applicability to the challenges of federalism. Applicable requirements were categorized in line with the following statement by Párraga Niebla [3, p. 231]: "public warning is effective if the following conditions are met: 1) the citizens at risk receive, notice, understand and trust warning messages on time; 2 ) the citizens at risk are prepared to act, i.e., are sufficiently familiar with warning procedures and trained to act upon”. As the latter is not within the scope of PWS, applicable requirements were categorized according to the first part of the statement. The statement was chosen as a framework as the paper ultimately aims to support the effectiveness of public warning, which is what Párraga Niebla [3] refers to.

To ensure the applicability and completeness of the requirements determined in the literature review, we conducted one expert interview with a focus on public warning in federal states. The interviewee is employed in the middle management of an agency for civil protection in a federal administration. The interview lasted 73 minutes, was recorded, and then transcribed. We analyzed the interview according to the specificities of public warning systems in federal states, corresponding requirements, and our design principles. Together with further insights from documents of other organizations involved in civil protection and hazard management, we obtained our final set of requirements. Based on these requirements, we proceeded with the development of our design principles. Design principles are artifacts that apply to a class of problems and 
go beyond a classical instantiation [19]. An iterative and incremental approach was chosen to derive the design principles. The authors took turns in developing first drafts and reviewing the other authors' work. In total, three iterations were carried out until the set of principles was finished. The IT artifact was developed argumentatively. Consequently, we created our artifact to offer guidelines for introducing or evaluating PWS in federal systems.

The preliminary Evaluation of the design principles was two-fold: First, we conducted a feature comparison [20] against the requirements a PWS in federal systems should meet. Second, we tested their applicability exemplary for the German case.

We already started with the Diffusion of our findings with a presentation in front of seven academic professionals and a group of 24 students. We are planning to further disseminate our work on the 16. Internationale Tagung Wirtschaftsinformatik.

\section{$4 \quad$ Requirements}

\subsection{Literature Review}

The literature review revealed applicable requirements in three out of the four conditions necessary to ensure effective public warning as referred to in the statement by Párraga Niebla, [3], in Section 2.2., namely "receive”, “understand" and "trust”. No requirements in the category "notice" were considered relevant to the specific challenges.

Receive. Seven applicable requirements aim to ensure that the population receives warning messages distributed by authorities. The first requirement refers to using $a$ multi-channel approach in order to reach all people threatened by a hazard in all contexts. Several sources concluded that a multi-channel approach increases the effectiveness of public warning or is less risky as all channels have limitations [4, 5, 14, 21-23]. Further supporting arguments insist on the need for (ubiquitous) coverage and high penetration of warning technologies [3, 24]. Furthermore, the population needs to be warned in different contexts, which cannot be reached by the same warning channels [3, 5, 8, 9]. Also, people's access to one technology (e.g., their mobile phone or specific applications) cannot be guaranteed [5, 25]. Brynielsson et al. [26] further reason that people's perceptions of source credibility and trust differ, which is another argument for using different channels to make PWS more effective.

Second, authorities should be able to activate all necessary channels easily and without issues [4]. Besides, channels and technologies should be compatible [16, 27]. In this context, Párraga Niebla et al. [4] refer to the introduction of the Common Alerting Protocol (CAP) as an essential step. Fourth, warnings should be sent based on citizens' current location (geotargeting) [3, 5, 8, 9, 14], in order to "avoid excessive panic" [24, p. 154]. Due to this requirement, cell broadcasting might not be an appropriate technology for large countries, as cells tend to cover large areas [5]. The fifth requirement relates to warning the population in a timely manner, not only but also by using appropriate technologies [3, 5, 8, 14, 16, 24, 26, 28]. Lastly, the literature stresses the need to use highly available [3], reliable and resilient [3, 5], as well as 
redundant [16] technologies to prevent failures. For federal countries, Aloudat and Michael [5] mention the need to establish clear protocols for information dissemination to ensure the correctness of the destination of the message which also relates to the trust in concept of trust later mentioned in this section.

Understand. Three distinct requirements aim to ensure that recipients of warning messages understand them. Firstly, when formulating and sending alerts, authorities should use a targeted approach by considering different needs and capabilities of the population, including for example age groups and people with disabilities [8, 27-29]. This also includes the support of (configuring) different presentation modes or multimedia content [3, 8]. Alerts via text messages might, for example, be very beneficial to deaf and hearing-impaired [5]. Secondly, alerts should be offered in a language understandable by the population, which implies the need to provide information in several languages $[3,5,8]$. Lastly, authorities should provide citizens with all or sufficient relevant information, including where to find further details [3, 4, 8], in a specific [26] and accurate manner [5].

Trust. Four applicable requirements were assigned to the category of "trust". Párraga Niebla [3], Preinersdorfer et al. [16], and Green et al. [30]mention the need for PWS to include security features. Examples of this can be authentication methods or limiting web-based access to PWS to prevent manipulation and cybersecurity threats. Further, it needs to be ensured that an "all-clear" message will be sent using the same communication channels once the threat is over [14]. Concerning the challenges for federal countries, Aloudat and Michael [5] note the necessity to ensure consistent quality at all locations, thus also across state borders. Experts interviewed by Aloudat and Michael [5] stated that every citizen is entitled to alerts of the same quality, leading to the need to specify guidelines by a central (national) agency on what that meant. Furthermore, the authors mention the need to establish clear protocols for information dissemination to ensure the correctness of the content of the message [5].

Further Requirements. Two federalism-specific requirements do not fall into the previously introduced categories. Firstly, Aloudat and Michael [5] mention the need for a common approach to public warning specified by a central (national) agency. Secondly, inadequate coordination is highlighted as the primary barrier for warning systems by three authors $[3,12,13]$, which supports the call for appropriate governance structures to mitigate this issue. Preinersdorfer et al. [16] hereby highlight that structures need to ensure that alerts can be sent from different administrative levels according to the prevailing disaster management structures.

\subsection{Document Analysis and Expert Interview}

Following the review of academic literature, further documents, for example, those published by international organizations, were used to validate the list of requirements. Additional sources put a specific emphasis on appropriate governance structures and clear responsibilities as well as standardized procedures and protocols to ensure effective warning of the population [31-33]. In addition, the European 
Telecommunications Standards Institute (ETSI) defines a list of scenarios in which citizens need to be reached [34]. It widens the definition of citizens at risk, including those "entering the area or in close proximity to the area during the emergency" [34, p. 9], which specifies the first requirement (see Receive) as derived from academic literature. One additional requirement, namely, to ensure appropriate training of warning personnel [32], was added to the list.

Besides, the requirements from the literature were cross-referenced with insight from the expert interview. Insights from the interview confirmed four requirements that had previously been identified by other sources: The need to use a multi-channel approach with technologies that provide attention-calling features, to reach all people at risk in all contexts and locations. As stated by the interviewee: "In our opinion there is not just one warning channel $[\ldots]$ because every warning channel has some advantages and disadvantages. The radio is still the most widespread warning multiplier $[\ldots]$ the disadvantage is that you do not wake up when the radio is switched off - you need something to wake people up with". The interviewee also emphasized the need to provide the population with "all clear" messages that "need to be formulated in such a way that the citizen understands it".

\section{$5 \quad$ Design Principles}

Based on the finalized list of requirements, we developed design principles in the areas strategy and governance, standards and templates, and technology. The design principles in the category strategy and governance aim for a common and jointly developed public warning concept, highlighting essential aspects that have to be considered and defined. For example, is it important to define clear responsibilities between federal, state, and local authorities to warn the population on time as well as with the appropriate means of public warning. However, a lower authority should be able to send warning messages to a larger territorial area within the same state if necessary. For this, the authority should receive prior approval from a respectively higher authority. The design principles in the category standards and templates focus on guaranteeing every citizen, no matter in which federal state they are located, the same quality of warning. This can be fulfilled by developing templates and offering training to responsible authorities. The last feature, technology, focuses on the implementation of the previously defined changes as well as the provision of the technologies.

Strategy and Governance. The principles in this category are based on the identified requirement to ensure a common approach as well as on establishing appropriate governance structures, including a description of responsibilities. A joint concept of strategy and governance supports the avoidance of coordination issues during an emergency between different levels of authorities and means of public warning. The following principles are defined:

(1) Federal authorities in coordination with state and local authorities work out and use a common concept to warn the public in case of occurring emergencies. 
(2) The concept should consider and define scenarios in which citizens need to be reached (e.g., at home, at work, outside, in transit, etc.) and assign at least one technology to each scenario. At least one technology needs to be used across the entire country, while further technologies can be specified individually by each authority.

(3) The concept should consider and define warning levels as a basis for assigning responsibilities as well as the choice of public warning means. For each warning level, it needs to be specified which scenarios need to be covered when sending a warning message.

(4) The concept should consider and define clear responsibilities based on warning levels and (territorial) administrative responsibilities. In predefined emergencies, authorities should be able to warn the population in proximity to but outside their jurisdiction. In order to reach out to a larger area, the responsible authority ${ }^{1}$ should receive prior approval from the respective higher administrative level.

(5) The concept should consider and define whether and when affected ${ }^{2}$ authorities are allowed to change or adapt a message passed on from the authority responsible for that disaster.

(6) The concept should consider and define whether responsibilities for warning messages and all-clear signals can change over the course of a disaster.

Standards and Templates. The design principles listed in the category standards and templates address the requirement category "understand", which considers different needs and capabilities of the population when sending alerts (targeted approach). To warn the whole country in case of an emergency, it is of high importance that every person can understand the message (provide information in several languages). The following principles are defined:

(7) Public warning messages should be based on common standards to ensure equal quality and understanding of messages for the entire population and avoid delays despite split responsibilities.

(8) The responsible authorities should jointly agree on standards for each technology/ means of warning (e.g. protocols for information dissemination) to ensure equal quality of warning in a timely manner.

(9) The responsible authorities should jointly agree on standards that consider the needs and capabilities of the population to avoid exclusion of parts of the population.

(10) The responsible authorities should jointly agree on standards which define templates for warning messages for each means of warning, to provide the same information to every citizen despite their source of information (e.g., relevant content, specific and accurate phrasing, languages).

(11) The responsible authorities should jointly agree on standards that define training guidelines. They should further ensure joint training and workshops to enable an

\footnotetext{
${ }^{1}$ The responsible authority is understood to be the authority responsible for sending out the initial warning message. The administrative level of the authority might depend on the warning level of the disaster.

2 The affected authority is understood to be an authority in (close) proximity of the disaster (but outside the jurisdiction/competence area of the responsible agency) which receives the warning message and can send it to its citizens.
} 
exchange of experiences among different levels. Thereby, every person in charge is able to use the provided standards and templates in a correct manner.

Technology. The last category, containing five design principles, addresses the formerly defined requirements of the category "receive". It is important that all citizens are able to receive the same warning message using a centrally provided technology, to avoid mixed information and late responses to the warning message. The following principles are defined:

(12) A (national) authority should provide basic infrastructure and interfaces for the PWS which can be accessed by all authorities involved in public warning. Thereby, it should be assured that this infrastructure is redundant and protected against failures.

(13) Furthermore, country-wide used technologies should be provided centrally (e.g., by a national authority or private provider), which allows states and municipalities to additionally connect further warning technologies. This provides a way to assure highly available, reliable, and resilient technologies are used.

(14) The technology of the PWS needs to ensure that all relevant scenarios according to warning levels are covered (e.g., by choice of at least one technology in that category) when sending a warning message. In each relevant scenario, at least the country-wide used technology needs to be used, in order to ensure that all people are reached in the same scenarios despite their location.

(15) Lastly, the responsibilities and access rights should be represented in the PWS and (16) the PWS should enable to reassign responsibility of a warning message to other levels in case of changing responsibilities (e.g., "all-clear" message from authority closest to disaster). The means used for updates of all-clear messages should not be adaptable over the course of the disaster.

\section{Exemplary Case Application: The German Case}

In Germany, warning and alerting the population is a task shared between the federal and state administrations. Whereas the federal administration is responsible for civil protection, especially in defense situations, the states are responsible for protecting the population in case of most other disasters [35]. For this purpose, the Federal Office of Civil Protection and Disaster Assistance (BBK) operates the Modular Warning System (MoWaS), which has been used by federal and state authorities since 2013 [36]. It allows the triggering of all connected warning technologies via a central user interface [36].

In order to uncover opportunities to further increase the effectiveness of public warning through MoWaS, the design principles were applied to the German case. Each principle was individually checked against information collected through the expert interview, analysis of available documents, and web research. In case the design principles were not fully adhered to, recommendations based on the design principles were formulated. In case information was limited due to access restrictions, for example, regarding higher warning levels, we focused on the parts of the system we did have information about. The opportunities for improvement were summarized in Table 1. 
Table 1. Opportunities for increasing the effectiveness of MoWaS

\begin{tabular}{|c|c|}
\hline$\#$ & Opportunity for improvement \\
\hline 1 & $\begin{array}{l}\text { The involved authorities should agree on a comprehensive warning concept which } \\
\text { brings together the information identified in different sources and defines clusters of } \\
\text { technologies (scenarios) as well as the respective, country-wide used technology for } \\
\text { each scenario. Responsibilities and rights should be clearly defined (including, for } \\
\text { example, exceptional situations and the right to warn neighboring municipalities). } \\
\text { The guidelines agreed upon by federal and state governments in } 2019 \text { [37] provide } \\
\text { a starting point to include these design recommendations. }\end{array}$ \\
\hline 2 & $\begin{array}{l}\text { Templates should be created for each means of public warning considering the needs } \\
\text { and capabilities of the population. The templates should include (only) the relevant } \\
\text { content and be explicitly phrased and accurately. Templates need to exist in different } \\
\text { languages. }\end{array}$ \\
\hline 3 & $\begin{array}{l}\text { The remaining authorities relevant for public warning from the different } \\
\text { administrative levels should be connected to MoWaS. }\end{array}$ \\
\hline 4 & $\begin{array}{l}\text { It should be ensured that the previously defined country-wide used technologies are } \\
\text { provided centrally for all citizens by public or private organizations, as are, for } \\
\text { example, NINA or KATWARN. }\end{array}$ \\
\hline 5 & $\begin{array}{l}\text { Changes based on the previous recommendations should be reflected in MoWaS, for } \\
\text { example through authorities' (access) rights and the obligation to choose country- } \\
\text { wide used technologies as well as predefined templates for warning messages. } \\
\text { Warning updates should only be possible using the same warning technologies. }\end{array}$ \\
\hline
\end{tabular}

It should be noted that the further development of MoWaS is and was the central concern of a project carried out jointly by federal and state governments. It aims to finish by the end of 2020 and is funded through the Internal Security Fund (ISF) [38]. Some of the recommendations, such as connecting the remaining authorities to MoWaS, might therefore already being addressed.

The exemplary application to the German case emphasizes that the proposed design principles can be a valid approach to assess a PWS in a federal administrative system. Despite not being able to evaluate all parts of the system due to restricted access to information, we could still derive recommendations that might be valuable for improving the effectiveness of MoWaS.

\section{$7 \quad$ Discussion and Conclusion}

We have developed a set of design principles in the categories strategy and governance, standards and templates, and technology that aim to guide through the implementation of a new PWS in federal administrative systems. Natural and human-made disasters can affect large areas of an authority's population. Equally, public warning has become more critical as a consequence of increasing and exacerbating numbers of incidents over the past years [28]. Even though technological development and digitalization have led to an improvement in PWS, administrative and governance structures also play an essential role in effective public warning, especially in complex systems as federalism [3, 5, 39]. 
To achieve the research goal, we conducted a systematic literature review on the requirements for public warning in federal administrative systems according to Webster and Watson [18], which detected three challenges of public warning in federal systems: missing clear responsibilities, lacking coordination, and interoperability. Furthermore, general requirements of a PWS, as well as federalism-specific requirements, have been identified. These requirements addressed the categories receive, notice, understand, trust as well as further requirements outside those categories. Based on the results of the literature review, the design principles were developed.

\subsection{Limitation and further research}

Despite basing the research design on proven research approaches, our work is subject to limitations that emphasize the need for further research. Firstly, the literature review, especially its manual steps, might be subjective to some extent. It could also be difficult to distinguish between generally relevant challenges and requirements as well as those that were only applicable in the case discussed by the authors of the article in question. Further, the literature review revealed only a limited literature basis for requirements regarding administrative structures and especially federalism. This fact was mitigated by consulting further documents in the following steps of the research.

Further research should, thus, aim to extend the literature basis in this field. Due to the increasing importance of public warning, scholars could, for example, compare the effectiveness of different public warning systems considering their academic background. Secondly, even though the basic phases for design-oriented IS research as proposed by Österle et al. [6] were followed to derive the IT artifact, the design principles were not finally evaluated by experts. Future research should aim to increase the involvement of experts in the field of PWS in federalism to verify and test the design principles, for example through focus groups. As a next step, research could test the design principles together with experts to investigate and improve its practical applicability.

Furthermore, part of the information regarding public warning in Germany is classified, which might have influenced the results of the demonstration. We are also not the intended addressees of the artifact. As we used only one case for demonstrating the artifact, we chose a case in which public warning is substantially influenced by the structures of the federal system [3]. This implies that it might indeed be strongly affected by the discovered challenges pose a good example for other cases. Scholars could now investigate the applicability of our design principles in other federal administrative systems, such as Belgium or Australia. Lastly, due to scope, we decided to apply only one iteration of Österle et al.'s [6] method. The decision to leave improvements of the artifact to the following projects, for example, due to the nature of research, is recognized as legitimate [40]. Even though further iterations might improve the artifact, it already provides a starting point for further research. It provides value to both theory and practice. Other researchers can for example use the artifact as groundwork and contribute to improving it with their own knowledge and experiences.

Most importantly, however, it should be kept in mind that, even though the focus of our research was solely on PWS, an effective PWS does not necessarily directly lead 
to an effective public warning. Citizens need to be appropriately prepared, for example, by being trained to act upon warning messages [3]. Therefore, future research should extend the design principles considering the preparation of citizens.

\subsection{Theoretical and practical implications}

Despite its limitations, we identified key implications for theory and practice which emerge from our research. Firstly, the literature review contributes to the closure of the identified research gap regarding effective PWS and federalism and highlighted the difference in the maturity of the research fields of general public warning (systems) and public warning in federalism. Secondly, the design principles provide a starting point for national governments and practitioners in responsible agencies to work with. They can be used as a basis for discussions with involved parties and draw attention to factors that are important for effective public warning. A validated set of design principles will eventually enable federal governments to review their overall warning systems and discover potentials for improvement. This is especially important considering a European Union directive that commits member states to have mobile number-based PWS (or equivalent regarding its effectiveness) in place by 21 June 2022 [41]. While it influences the choice of warning technologies included in a multi-channel approach for public warning, it also generally implies the necessity for a review of existing PWS and used technologies. Thirdly, not only federal governments can benefit from the results of this paper. As stated by Gregor and Hevner, an "artifact that is presented with a higher level degree of abstraction can be generalized to other situations" [19, p. 352]. The design principles were kept on a reasonably abstract level; thus, any national government can use an adapted version of the model as guidance for a review of its PWS. An essential step of the process was to gather overall requirements for effective PWS, which can be used as a basis to design an improved system. Lastly, irrespective of the administrative level, state or local governments can refer to the design principles to drive bottom-up change, which is especially important as they are close to the citizens and might be the first to sense when changes in an existing system become necessary.

\subsection{Conclusion}

All in all, the study contributes to filling a research gap, as well as enabling governments to identify federal specific areas of improvement in their existing PWS or guide the introduction of PWS in federal systems. Eventually, this way the use of our design principles can lead to a more effective public warning system. This might in turn positively influence the trust of the public in the warning system as well as the awareness of measures in case of disasters. In the case of Germany, a more effective public warning system might lead to a more positive connotation of the subject and a higher acceptance during the next "Warntag” (Warning Day). 


\section{References}

1. Bundesministerium des Innern für Bau und Heimat: Probealarm zum "Warntag 2020" fehlgeschlagen, https://www.bmi.bund.de/SharedDocs/pressemitteilungen/DE/2020/09/ warntag-fehlgeschlagen.html.

2. Die Zeit: App-Alarm stark verzögert: Der Warntag wird zum Fehlschlag, https://www.zeit.de/news/2020-09/10/erster-bundesweiter-warntag-um-11-uhr-heulen-diesirenen.

3. Párraga Niebla, C.: Communication Technologies for Public Warning. In: Wireless Public Safety Networks 1: Overview and Challenges. pp. 229-260. Elsevier Inc. (2015).

4. Párraga Niebla, C., Mulero Chaves, J., De Cola, T.: Design Aspects in Multi-channel Public Warning Systems. In: Wireless Public Safety Networks 2: A Systematic Approach. pp. 227261. Elsevier Inc. (2016).

5. Aloudat, A., Michael, K.: Toward the regulation of ubiquitous mobile government: A case study on location-based emergency services in Australia. Electron. Commer. Res. 11, 3174 (2011).

6. Österle, H., Becker, J., Frank, U., Hess, T., Karagiannis, D., Krcmar, H., Loos, P., Mertens, P., Oberweis, A., Sinz, E.J.: Memorandum on design-oriented information systems research. Eur. J. Inf. Syst. 20, 7-10 (2011).

7. ISDR: Terminology: basic terms of disaster risk reduction, /www.unisdr.org/eng/library/libterminology-eng home.htm.

8. Mulero Chaves, J., De Cola, T.: Public Warning Applications: Requirements and Examples. In: Wireless Public Safety Networks 3: Applications and Uses. pp. 1-18. Elsevier (2017).

9. Crowe, A.: When Status Quo Becomes Obsolete: The Changing Use of Outdoor Warning Sirens. J. Homel. Secur. Emerg. Manag. 7, 1-5 (2010).

10. Jagtman, H.M.: Cell broadcast trials in The Netherlands: Using mobile phone technology for citizens' alarming. Reliab. Eng. Syst. Saf. 95, 18-28 (2010).

11. Corfee-Morlot, J., Cochran, I., Hallegatte, S., Teasdale, P.-J.: Multilevel risk governance and urban adaptation policy. Clim. Change. 104, 169-197 (2011).

12. Wolf, F., Pfohl, T.: Protecting the population in a multilevel system: horizontal and vertical informal governance patterns in Germany. Zeitschrift fur Vergleichende Polit. 8, 259-285 (2014).

13. Marchezini, V.: "What is a Sociologist Doing Here?” An Unconventional People-Centered Approach to Improve Warning Implementation in the Sendai Framework for Disaster Risk Reduction. Int. J. Disaster Risk Sci. 11, 218-229 (2020).

14. Karutz, H., Geier, W., Mitschke, T.: Bevölkerungsschutz. Springer, Berlin, Heidelberg (2017).

15. Reed, K.: Disaster relief. Nova Science Publishers, Hauppauge, NY (2011).

16. Preinerstorfer, A., Egly, M., Gojmerac, I., Hochwarter, C., Schuster, C., Stocker, R.: Requirements for the next generation Public Warning and Alert System for Austria. In: Proceedings of the 14th International Conference on Telecommunications - ConTEL 2017. pp. 115-122. Institute of Electrical and Electronics Engineers Inc., Zagreb, Croatia (2017).

17. Dittmer, C., Lorenz, D.F.: Disaster Situation and Humanitarian Emergency - In-Between Responses to the Refugee Crisis in Germany. Int. Migr. (2019).

18. Webster, J., Watson, R.: Analyzing the Past to Prepare for the Future: Writing a Literature Review. MIS Q. 26, XIII-XXIII (2002).

19. Gregor, S., Hevner, A.R.: Positioning and Presenting Design Science Research for Maximum Impact. MIS Q. 37, 337-355 (2013). 
20. Siau, K., Rossi, M.: Evaluation techniques for systems analysis and design modelling methods - a review and comparative analysis. Inf. Syst. J. 21, 249-268 (2011).

21. Alhmoudi, A.A., Aziz, Z.: Integrated framework for early warning system in UAE. Int. J. Disaster Resil. Built Environ. 7, 361-373 (2016).

22. Nakamura, I., Morioka, C.: Effect of communication regarding dam operation on the evacuation of residents: A case study of the 2018 inundation of the Hijikawa river in Japan. Geosciences. 9, 444 (2019).

23. Rodríguez, H., Donner, W., Trainor, J.E.: Handbook of Disaster Research. Springer International Publishing, Cham (2018).

24. Zhang, H., Wang, G., Lu, M., Wang, D., Xu, P.: Emergency warning and bidirectional communication via digital audio broadcast. IEEE Trans. Consum. Electron. 65, 150-159 (2019).

25. Jasmontaite, L., Dimitrova, D.: Online Disaster Management: Applicability of the European Data Protection Framework and Its Key Principles. J. Contingencies Cris. Manag. 25, 2330 (2017).

26. Brynielsson, J., Granåsen, M., Lindquist, S., Narganes Quijano, M., Nilsson, S., Trnka, J.: Informing crisis alerts using social media: Best practices and proof of concept. J. Contingencies Cris. Manag. 26, 28-40 (2018).

27. Malizia, A., Onorati, T., Diaz, P., Aedo, I., Astorga-Paliza, F.: SEMA4A: An ontology for emergency notification systems accessibility. Expert Syst. Appl. 37, 3380-3391 (2010).

28. Basher, R.: Global early warning systems for natural hazards: Systematic and peoplecentred, (2006).

29. Marchezini, V., Trajber, R., Olivato, D., Muñoz, V.A., de Oliveira Pereira, F., Oliveira Luz, A.E.: Participatory Early Warning Systems: Youth, Citizen Science, and Intergenerational Dialogues on Disaster Risk Reduction in Brazil. Int. J. Disaster Risk Sci. 8, 390-401 (2017).

30. Green, A., Dodson, K., Woszczynski, A.B., Easton, P.: Responding to cybersecurity challenges: Securing vulnerable U.S. emergency alert systems. Commun. Assoc. Inf. Syst. 46, 187-208 (2020).

31. European Emergency Number Association (EENA): Public Warning. V3.0. (2019).

32. UN Inter-Agency Secretariat of the International Strategy for Disaster Reduction: Developing Early Warning Systems: A Checklist. , Bonn (2006)

33. United Nations: Sendai Framework for Disaster Risk Reduction 2015-2030. , Geneva, Switzerland (2015).

34. European Telecommunications Standards Institute: TS 102182 - V1.4.1 - Emergency Communications (EMTEL); Requirements for communications from authorities/organizations to individuals, groups or the general public during emergencies. , Sophia Antipolis Cedex, France (2010).

35. Bundesamt für Bevölkerungsschutz und Katastrophenhilfe: Wie werde ich gewarnt?, https://www.bbk.bund.de/DE/AufgabenundAusstattung/Krisenmanagement/WarnungderB evoelkerung/Wie_werde_ich_gewarnt/Wie_werde_ich_gewarnt_node.html;jsessionid=272 A501B9976A8A7C2610B5F31553F10.2_cid355\#doc12868476bodyText5.

36. Bundesamt für Bevölkerungsschutz und Katastrophenhilfe: Das Modulare Warnsystem des Bundes und der Länder (Zusatzinformation). , Bonn.

37. Bundesamt für Bevölkerungsschutz und Katastrophenhilfe: Leitlinien für ein Gemeinsames Warnkonzept von Bund und Ländern. , Bonn (2019).

38. Bundesamt für Bevölkerungsschutz und Katastrophenhilfe: BBK Bevölkerungsschutz 1 | 2018. (2018). 
39. Scholta, H., Niemann, M., Halsbenning, S., Räckers, M., Becker, J.: Fast and Federal Policies for Next-Generation Federalism in Germany. In: Proceedings of the 52nd Hawaii International Conference on System Sciences (HICSS). pp. 3273-3282 (2019).

40. Peffers, K., Tuunanen, T., Rothenberger, M.A., Chatterjee, S.: A Design Science Research Methodology for Information Systems Research. J. Manag. Inf. Syst. 24, 45-77 (2008).

41. European Parliament: Directive (EU) 2018/1972 of the European Parliament and of the Council of 11 December 2018 establishing the European Electronic Communications Code (Recast) (Text with EEA relevance). (2018). 